\title{
On the porosity of barrier layers
}

\author{
J. Mignot ${ }^{1}$, C. de Boyer Montégut ${ }^{2}$, and M. Tomczak ${ }^{3}$ \\ ${ }^{1}$ IPSL/LOCEAN, UPMC/CNRS/IRD/MNHN, Paris, France \\ ${ }^{2}$ Laboratoire d'Océanographie Spatiale, IFREMER, centre de Brest, France \\ ${ }^{3}$ School of Chemistry, Physics and Earth Sciences, Flinders University of South Australia, Adelaide, Australia
}

Received: 14 April 2009 - Published in Ocean Sci. Discuss.: 28 April 2009

Revised: 20 August 2009 - Accepted: 5 September 2009 - Published: 28 September 2009

\begin{abstract}
Barrier layers are defined as the layer between the pycnocline and the thermocline when the latter are different as a result of salinity stratification. We present a revisited 2-degree resolution global climatology of monthly mean oceanic Barrier Layer (BL) thickness first proposed by de Boyer Montégut et al. (2007). In addition to using an extended data set, we present a modified computation method that addresses the observed porosity of BLs. We name porosity the fact that barrier layers distribution can, in some areas, be very uneven regarding the space and time scales that are considered. This implies an intermittent alteration of air-sea exchanges by the BL. Therefore, it may have important consequences for the climatic impact of BLs. Differences between the two computation methods are small for robust BLs that are formed by large-scale processes. However, the former approach can significantly underestimate the thickness of short and/or localized barrier layers. This is especially the case for barrier layers formed by mesoscale mechanisms (under the intertropical convergence zone for example and along western boundary currents) and equatorward of the sea surface salinity subtropical maxima. Complete characterisation of regional BL dynamics therefore requires a description of the robustness of BL distribution to assess the overall impact of BLs on the process of heat exchange between the ocean interior and the atmosphere.
\end{abstract}

\section{Introduction}

Generally, the base of the oceanic mixed layer coincides with the top of the pycnocline (Fig. 1, left). When a barrier layer (BL) is present the density change responsible for the pycnocline is produced by a salinity change, the mixed layer salin-

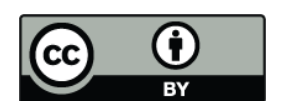

Correspondence to: J. Mignot (juliette.mignot@locean-ipsl.upmc.fr) ity being lower than the salinity in the layer below (Fig. 1, right). The $\mathrm{BL}$ is then defined as the layer between the pycnocline and the thermocline, which is found at greater depths. In this case, the temperature in the BL, immediately below the surface mixed layer, is thus either the same or slightly higher than the temperature in the mixed layer itself. BLs received their name (Godfrey and Lindstrom, 1989) from their property of inhibiting turbulent and entrained heat exchange between the atmosphere and the cold subsurface ocean. They can form under various mechanisms (see de Boyer Montégut et al. (2007) and Mignot et al. (2007) and references therein). Strong shallow salinity stratification can arise from intense precipitation (as under the ITCZ in the equatorial Pacific), river outflow (in the Bay of Bengal and close to the mouth of the Amazon), or subduction at the eastern edge of the Pacific Warm Pool. Mesoscale processes and Ekman vertical pumping can also contribute significantly to the formation mechanisms as well as large scale layering.

An early analysis of the distribution of the barrier layer for the global tropical ocean (Sprintall and Tomczak, 1992) was based on the first available version of the World Ocean Atlas (Levitus, 1982). De Boyer Montégut et al. (2007) and Mignot et al. (2007) recently extended the analysis to the global ocean, using a much larger and not already interpolated observational data base (more than 500000 temperature and salinity profiles from the period 1967-2002 and Argo profiles collected from 1996 until January 2006). These studies show the barrier layer thickness derived as the mean or the median from all available observations, for the four seasons. They allow researchers and others to identify ocean regions where heat exchange between the atmosphere and the subsurface ocean is inhibited.

Yet, when one of us (M.T.) investigated occurrences of barrier layers in the central Pacific Ocean as part of the science program of voyage S216 on SSV Robert C. Seamans of the Sea Education Association, it became evident that there was spatial variability in not only the thickness of BLs but

Published by Copernicus Publications on behalf of the European Geosciences Union. 

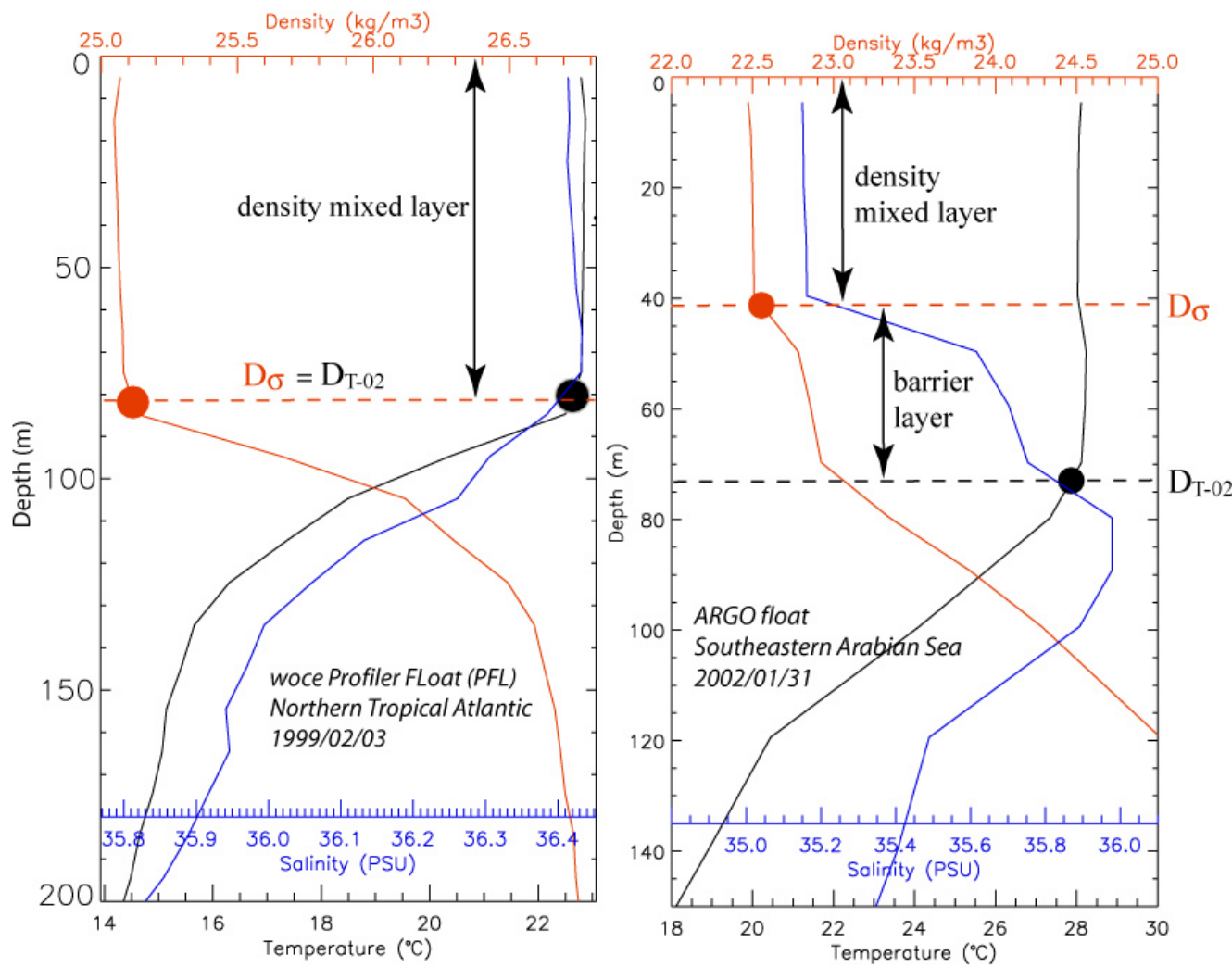

Fig. 1. Examples of obseved hydrographic profiles. Temperature (black), salinity (blue), and density (red) profiles are measured (a) from a WOCE profiler float on 3 February 1999 in the northern tropical Atlantic and (b) from an Argo float on 31 January 2002 in the southeastern Arabian Sea (de Boyer Montégut et al., 2007). Note the different vertical and horizontal scales used for the two profiles. The red solid dot shows the depth where the density criteria is reached, thus defining $D_{\sigma}$ (see text). The black solid dot shows the depth where the temperature criteria is reached, thus defining $D_{T-02}$ (see text). Figure 1a is an example where both criteria are reached at the same depth, and there is no BL. Figure $1 \mathrm{~b}$ is an example of classic BL case, where the temperature is approximately homogeneous below the density mixed layer. In this case, $D_{\sigma}$ and $D_{T-02}$ are different and they limit the barrier layer (BL). See Fig. S1 for an additional example (see http://www.ocean-sci.net/5/379/2009/os-5-379-2009-supplement.pdf).

also their presence/absence (Fig. 2). The observed patchiness has the potential to modify the importance of the BL on airsea heat exchange, since the BL can only effectively obstruct the heat transfer if it is sufficiently persistent or if it is continuous over a sufficiently large area. If the barrier layer is dotted with "holes", in other words if it is relatively "porous", its role as an inhibitor of heat transfer can be greatly reduced, to the extent that the area available in the "holes" may allow turbulence and entrainment to act in the normal way. Regarding temporality, Sprintall and McPhaden (1994) investigated the persistence of BLs using mooring data at $0^{\circ}, 165^{\circ} \mathrm{E}$. They estimated the dominant timescale of BL thickness in the western equatorial Pacific to be around 12-25 days. This is less than a month. Given these observed characteristics of the $\mathrm{BL}$, what is the meaning of a $2^{\circ} \times 2^{\circ}$-monthly climatology?

To investigate this issue further, we propose to repeat the analysis of de Boyer Montégut et al. (2007) with a slightly amended methodology. The 2007 analysis determines the BL thickness as the median from all available observations, in- cluding stations with no barrier layer. This methodology was directly inspired from the computation of the mixed layer depth by de Boyer Montégut et al. (2004). However, while the mixed layer, as a fluid surface boundary layer, is a permanent feature of the ocean, BLs are not necessarily present in the ocean. They can appear or disappear according to the space and time scales of their formation and destruction mechanisms. BLs distribution at a specific grid point is thus not necessarily Gaussian but rather skewed toward high values. As a result, the former approach on a $2^{\circ} \times 2^{\circ}$-monthly grid possibly underestimated the BL thickness when it really occurs. In the present work, we determine the median thickness of all stations that effectively exhibit a barrier layer. In addition, we calculate the ratio $\mathrm{R}$ of the number of stations where a barrier layer exists to the total number of stations. This ratio can be considered as a measure of BL persistence. We define the porosity of the barrier layer as the quantity 1-R. Our goal is to estimate the BL robustness on a global scale regarding our time/space resolution. In some areas, thick BLs 


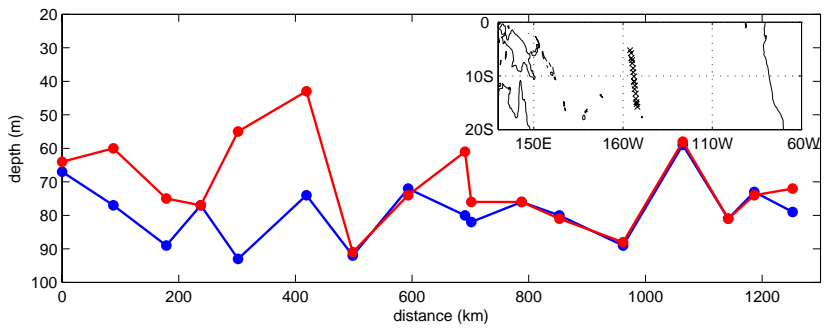

Fig. 2. Thermocline (blue) and pycnocline (red) depths measured in the central Pacific from $5^{\circ} \mathrm{S}$ to $15^{\circ} \mathrm{S}$ along approximately $155^{\circ} \mathrm{W}$ during the science program of voyage S216 on SSV Robert C. Seamans of the Sea Education Association (map in the top right corner, the crosses indicate the stations, the voyage was undertaken southward). The measurements took place between 17 and 26 April 2008. The thermocline and pycnocline depths are defined as the depths $D_{T-0.2}$ and $D_{\sigma}$ respectively in de Boyer Montégut et al. (2007) (see Sect. 2.2). Stations where the pycnocline is shallower than the thermocline are stations where a barrier layer was detected.

may occur but were not obvious in our previous studies as they are not persistent and/or do not occur on a large enough scale. This new study allows a better identification of such porous BLs that should then be considered carefully regarding their possible climatic impact on air-sea interaction.

The following section presents the new data set and the new methodology in more detail. The results are presented in Sect. 3, discussed in Sect. 4 and summarized in Sect. 5.

\section{Data and methodology}

\subsection{Data}

The present study is based on the collection of about 750000 instantaneous temperature and salinity profiles measured between 1967 and September 2008 (Fig. 3). They were obtained from the World Ocean Database (WOD) 2005 at the National Oceanographic Data Center (NODC) (Boyer et al., 2006), the World Ocean Circulation Experiment (WOCE) database (WOCE Data Product Committee, 2002), and the ARGO data base (from Coriolis Global Data Assembly Center). The previous study by de Boyer Montégut et al. (2007) was based on the same data base but included only data until January 2006 for the ARGO data base and until end of 2002 for the NODC (WOD2001) and WOCE data bases.

The 2007 study did not include statistical information. The major reason for this was the relatively small number of profiles available in some locations (Fig. 2a in de Boyer Montégut et al., 2007), which put the significance of the statistics into question. Extending the period from January 2006 to September 2008 provides an additional 200000 profiles and therefore improves the application of statistical analysis.

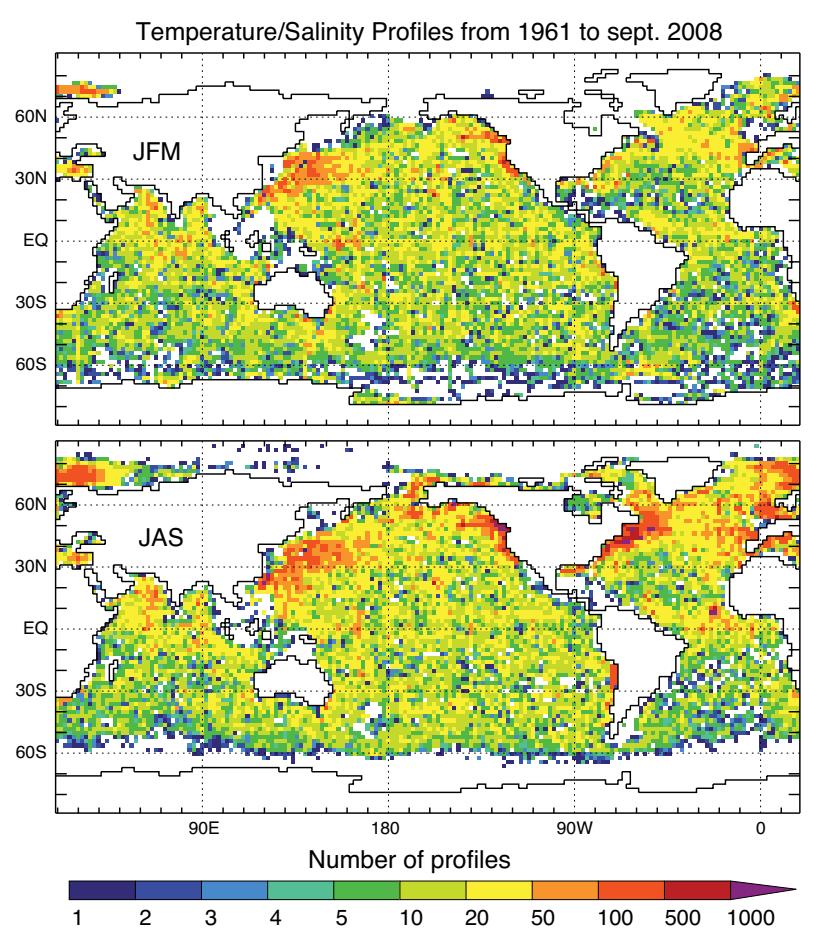

Fig. 3. Distribution of profiles including both temperature and salinity data in each $2^{\circ}$ by $2^{\circ}$ mesh box. JFM and JAS indicate the two seasons January-February-March and July-August-September, respectively. This figure should be compared with Fig. 2a in de Boyer Montégut et al. (2007).

\subsection{Methodology}

As in de Boyer Montégut et al. (2007) and Mignot et al. (2007), we compute the BL thickness for each profile based on the difference between two depths: $D_{T-02}-D_{\sigma}$ (see Fig. 1). $D_{T-0.2}$ is the depth where the temperature has decreased by $0.2^{\circ} \mathrm{C}$ as compared to the temperature at the reference depth of $10 \mathrm{~m}$. $D_{\sigma}$ is the depth where the potential density $\sigma_{\theta}$ has increased from the reference depth by a threshold $\Delta_{\sigma}$ equivalent to the density difference for the same temperature change at constant salinity:

$\Delta_{\sigma}=\sigma_{\theta}\left(T_{10}-0.2, S_{10}, P_{0}\right)-\sigma_{\theta}\left(T_{10}, S_{10}, P_{0}\right)$

$T_{10}$ and $S_{10}$ are the temperature and salinity at the reference depth $10 \mathrm{~m}$ and $P_{0}$ is the pressure at the ocean surface. If the difference $D_{T-02}-D_{\sigma}$ is positive, the pycnocline is shallower than the thermocline and a BL occurs with BL thickness equal to $D_{T-02}-D_{\sigma}$ Note that the layer comprised between the surface and $D_{T-0.2}$ can be isothermal but this is not general, as shown by the presence of subsurface temperature maxima in de Boyer Montégut et al. (2007). If the difference $D_{T-02}-D_{\sigma}$ is negative, the pycnocline is deeper than the corresponding thermocline. No BL occurs in this case but there is a deoth range over which the density change due to the 
temperature change is compensated by the effect of a salinity change (de Boyer Montégut et al., 2004).

In order to reduce these individual data over the $2^{\circ} \times 2^{\circ}$ grid, we first repeat the method employed in de Boyer Montégut et al. (2007) and Mignot et al. (2007) by defining the BL thickness as the positive values of the median of all differences $D_{T-0.2}-D_{\sigma}$ available for each grid mesh. This estimation thus mixes together profiles with real BL events and profiles where no BL is present $\left(D_{T-0.2}-D_{\sigma} \leq 0\right)$. The interpretation of this climatology is that for each grid point, the likelihood that a profile has a BL thickness larger than the given value is $50 \%$ and equals the likelihood that its BL thickness is smaller than the given value.

It is obvious that this methodology underestimates the barrier layer thickness that really occurs, although it is impossible to tell to what degree, since the monthly charts do not contain information about the number of stations without a barrier layer. In other words, they do not include information on the BL patchiness as observed in the central Pacific (Fig. 2). Therefore, we propose to compare this analysis with a slightly amended one: for each grid mesh, we now select profiles that do exhibit a significant BL before computing the median. The selection criterion, applied to each profile, is arbitrarily fixed to

$$
\left\{\begin{array}{l}
D_{T-0.2}-D_{\sigma}>\quad 5 \mathrm{~m} \\
D_{T-0.2}-D_{\sigma}>10 \%\left(D_{T-0.2}\right)
\end{array}\right.
$$

Note that in the previous approach, for clarity of the figures, we had arbitrarily chosen to shade grid points where the final median value met these criteria (see figures in de Boyer Montégut et al., 2007 and Mignot et al., 2007). But all profiles were used for the computation and the data product includes all final values. Here, the computation excludes profiles that do not meet these criteria. For all profiles, we use the complete initial vertical resolution and not the standard depth casts. For data from WOD2005, in particular, we thus have a vertical resolution of the order of $2 \mathrm{~m}$. We are aware however that the first condition $\left(D_{T-0.2}-D_{\sigma}>5 \mathrm{~m}\right)$ can be at the limit of the vertical resolution of the data, for ARGO floats in particular. However, as in de Boyer Montégut et al. (2004), a linear interpolation between observed levels is used for each profile to estimate the exact $D_{T-0.2}$ and $D_{\sigma}$. Furthermore, inspection of individual profiles confirmed the existence of BLs of less than 10m thickness (Fig. S1, see http://www.ocean-sci.net/5/ 379/2009/os-5-379-2009-supplement.pdf). BL porosity was consequently reduced by up to $25 \%$ in the deep Tropics when the threshold was increased to $10 \mathrm{~m}$. This collection of arguments motivated the choice of this condition. The second condition $\left(D_{T-0.2}-D_{\sigma}>10 \%\left(D_{T-0.2}\right)\right)$ is particularly needed in the extra-tropics where isopycnal and mixed layers are relatively deep so that an absolute difference of $5 \mathrm{~m}$ does not have the same meaning and impact as in the tropics. In order to give more robustness to the statistics, we only consider grid points where at least 5 profiles are available.
In both approaches, no kriging of the final data is applied in order to keep a point-wise interpretation of the comparison.

In addition to the BL thickness itself, the second approach provides statistics on the amount of profiles with a BL satisfying the criterion (Eq. 2) compared to the total number of profiles available at the specific grid point with both $D_{T-0.2}$ and $D_{\sigma}$ defined. This ratio $\mathrm{R}$ can be interpreted as a measure of the BL persistence: it gives information on the robustness of the measured BL as compared to the totality of the measurements that were done at the location. We define the BL porosity as the quantity (1-R) expressed in percent. The greater the BL porosity, the more uneven the distribution of the BL with respect to the space/time scale considered and the greater the transmissivity of the region. By using the term "porosity", we deliberately propose an analogy with the situationin porous rocks where water can pass through the crevices and other openings but not through the rock itself. Note that this concept of BL porosity is close to the concept of sea ice concentration that defines, for a given grid point, the percentage of area covered by sea ice.

\section{Results}

\subsection{BL porosity}

Monthly maps of BL porosity on the global $2^{\circ} \times 2^{\circ}$ grid are shown on Fig. 4. In several areas, BL porosity is less than $25 \%$, i.e. the majority of available profiles show a significant BL thickness. In these areas, the BL can thus be considered as a robust, non-transmissive feature and the heat transfer from the atmosphere to the ocean is quasi-permanently hindered for the observed month. In the tropics, these areas are essentially the ones that Mignot et al. (2007) highlighted as the thickest and the most persistent: the Bay of Bengal and the southeastern Arabian Sea, where the BL thickness peakes in February, the eastern tropical Indian Ocean, peaking in November, the northwestern tropical Atlantic, the western Mediteranean Sea, peaking in boreal winter, and finally the Pacific warm pool and the South Pacific Convergence Zone (SPCZ) where the BL thickness is maximum in austral autumn and winter. As detailed in Mignot et al. (2007), these BLs are due to the large scale advection of various freshwater sources (river outflow and precipitation). Thus, they extend over macro-areas and they are logically not very porous. They are also expected to have a real and robust impact on air-sea exchanges (the quantification of the latter is beyond the scope of the present paper).

Permanent differences between $D_{T-02}$ and $D_{\sigma}$ are also detected at high latitudes in winter (North Pacific, Labrador Sea, Norwegian Sea and Austral Ocean south of $50^{\circ} \mathrm{S}$ ). As discussed in de Boyer Montégut et al. (2007), these differences are due to the layering of different water masses rather than air-sea interface physics. Their low porosity results from this large scale characteristic. However, their climatic 


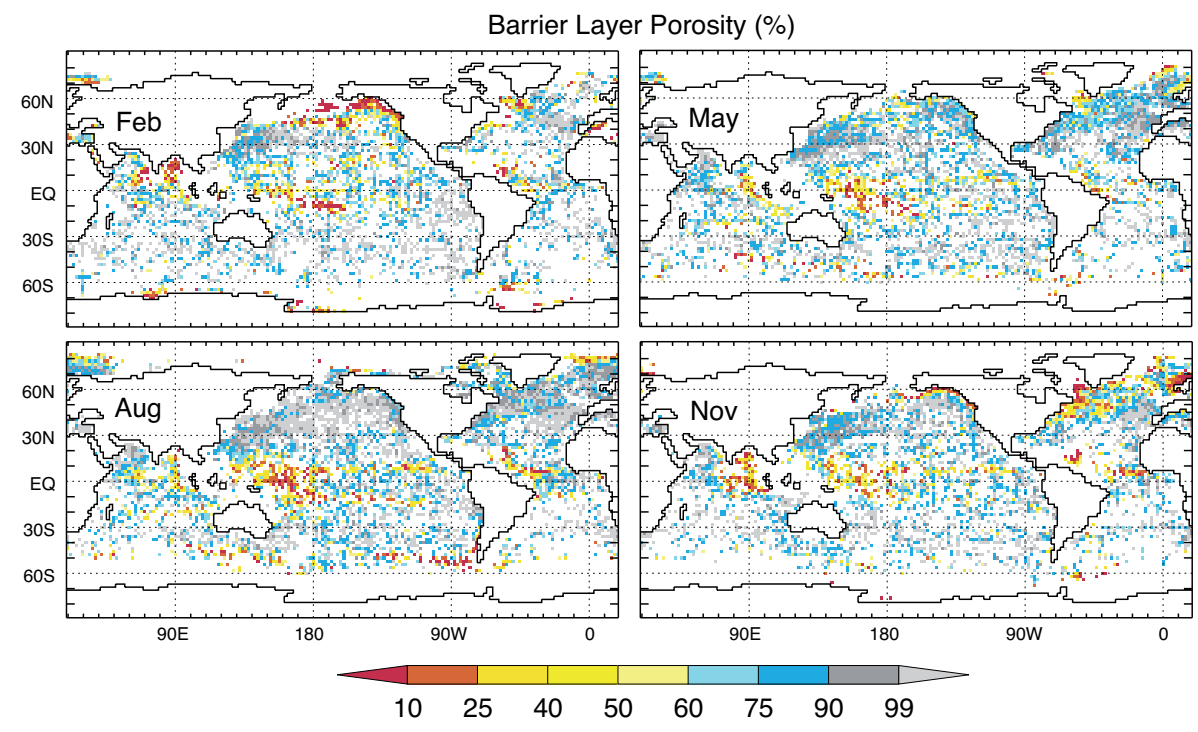

Fig. 4. Selection of 4 monthly maps showing the BL porosity measured as $100 *(1-\mathrm{R})$, where $\mathrm{R}$ is the ratio of the number of profiles where a significant BLT is detected over the total number of profiles available at this location with $D_{T-02}$ and $D_{\sigma}$ both defined. Light grey oceanic areas show grid points where BL porosity is $100 \%$, i.e. no BL was ever detected. White areas show grid points where less than 5 profiles where available with both $D_{T-02}$ and $D_{\sigma}$ defined. See Fig. S2 for the full 12 monthly maps.

impact is probably limited because they occur at greater depths, since the winter mixed layer is deep at these latitudes (below $100 \mathrm{~m}$ in the North Pacific and $200 \mathrm{~m}$ in the Labrador Sea). Therefore, we do not comment further on the potential climatic role of the BLs detected in these regions. Note that significant BL thickness also appears in the south-east Pacific, where the SubAntarctic Mode Water is formed. It is beyond the scope of the present study to investigate its origin in detail but since many recent studies point to this region and this water mass as carrying signatures of climate change through direct air-sea interaction and subduction of gases, this should be done in a following study.

Next, Fig. 4 also contains areas where the BL porosity is comprised roughly between 25 and $60 \%$. In particular, porosity index under the central and eastern Pacific ITCZ away from the warm pool is around $25-40 \%$ in boreal summer. This value suggests that $1 / 2$ to $3 / 4$ of the summer profiles collected in this area exhibit a BL. Another way to see this value is that BLs detected in this area persist over slightly more than half of the sampling time, that is one month here. This porosity ratio can be linked to the BL formation mechanism: under the ITCZ, mesoscale turbulent activity is thought to play an important role in generating BLs (e.g. You, 1995, Cronin and McPhaden, 2002). Since this activity is not resolved by our $2^{\circ} \times 2^{\circ}$ monthly grid, we do expect a relatively high porosity ratio (it increases to up to $75 \%$ in boreal winter). It becomes evident here that the notion of porosity cannot be separated from the time and space scale of the study.

Another major area of porous tropical BL is the southern Arabian Sea in summer, studied recently by Thadathil et al.
(2008). This BL area was already detected in Mignot et al. (2007) but it had not been commented upon because of its small thickness. The present analysis emphasizes that it is not necessarily thin but rather porous (about $50 \%$ or more). de Boyer Montégut et al. (2009) show that during this season, BL formation is linked to the southward displacement of a high salinity front and its associated mesoscale instabilities. This mechanism is consistent with a relatively porous BL. Note also the intermediate porosity ratio of the winter BL located offshore of California and already mentioned in de Boyer Montégut et al. (2007).

Winter BLs located equatorward of the subtropical SSS maxima were one of the major findings of Mignot et al. (2007). It was shown that their formation mechanism is still under discussion, with the relative influence of the large scale layering of different water masses on the one hand, and of seasonal vertical turbulent mixing on the other hand not being well established. These BLs clearly appear in Fig. 4 with intermediate porosity indexes, generally less than $50 \%$. This tends to confirm some influence of turbulent mixing below the $2^{\circ}$-monthly scales, at least that subsurface advection of salty waters is not the only factor inducing the formation of these BLs.

Figure 4 also reveals several grid points where the porosity index amounts to $60-90 \%$. This corresponds to very porous BLs, which probably have a relatively limited impact on airsea heat exchange and thus climate. Indeed, in this case, the exchange of heat between the mixed layer and the ocean interior is perturbed by an intermittent BL, but it is not permanently blocked. Figure 4 shows that such intermittent BLs are potentially present in all regions of the globe, in any 
season in the tropics and mostly in winter in the mid to high latitudes. They are also detected along the western boundary currents in summer, especially along the Gulf Stream. In this region, indeed, BLs may occur due to mesoscale eddies coming from instabilities of the current and bringing fresh water lenses from the north (de Boyer Montégut et al., 2007 and references therein). This formation mechanim is again consistent with the transient feature revealed by Fig. 4 .

Finally, the figure still reveals areas where no BLs are ever detected (porosity above 90\%). These are essentially the winter mid-latitudes (compensation areas) and the summer northern mid-latitudes (except along the western boundary currents as indicated above).

\subsection{BL thickness}

We compare now the BL thickness given by the approach developed here (Fig. 5) with the one developed in de Boyer Montégut et al. (2007) and Mignot et al. (2007) updated with the new data set (not shown - see online supplementary material: http://www.ocean-sci.net/5/379/2009/ os-5-379-2009-supplement.pdf). The first thing to note is that the new computation retrieves many more climatological barrier layers than when all stations are used to compute the final median value of the BL thickness, and that BLs computed by the $n$ ew approach are naturally generally thicker than the ones computed by the former method (Fig. 6). Differences are mostly evident in areas where the BL porosity (Fig. 4) is intermediate to high (40 to $90 \%$ ). Indeed, in these regions, a large proportion of profiles without barrier layers pushes the median toward a very low value of BL thickness if they are included in the computation. On the other hand, a low porosity (say less than 30 to $40 \%$ ) means that the majority of the collected profiles are captured by the criterion given in Eq. (2), so that the two methods become equivalent. And when a BL is too porous (more than $90 \%$ ), it is most probably very thin, so that both approaches also give similar values. Therefore, the major significant finding of this new product concerns BLs of intermediate porosity. In this case, the 2007 method takes a large amount of profiles that do not present a significant BL into account so that it strongly underestimates the resulting BL thickness.

In the tropics and subtropics, the maps of differences (Fig. 6) are rather patchy. Consistent with the discussion above, differences are small (generally less than $5 \mathrm{~m}$ ) in the tropical Indian Ocean, the Pacific warm pool, under the SPCZ and in the northwestern tropical Atlantic. They can amount to $10-25 \mathrm{~m}$ in the central equatorial Pacific and to 5$10 \mathrm{~m}$ in the central equatorial Atlantic (under the ITCZ). In the Indian Ocean, some significant differences are visible in the Bay of Bengal in March, in the northern Arabian Sea in January and February and in the southern Arabian Sea in August. Figure 4 revealed a higher porosity ratio during these specific months than during the rest of the year. As reviewed in Mignot et al. (2007), these months correspond to the end of the thick BL cycle at the corresponding location, so that it is not surprising to detect less BLs, particularly towards the end of the month. In this respect, this new approach of the BL thickness computation can also give insight into the characterization of BL seasonality. Finally, we note differences up to $30 \mathrm{~m}$ in thickness for BLs located equatorward of the subtropical SSS maxima in winter. This amounts to 40 to $70 \%$ of the BL thickness computed by the new approach.

Large differences (Fig. 6) are also found at mid to high latitudes in winter. In these areas, BLs can indeed be very thick (over 150-200 m, de Boyer Montégut et al., 2007), so that incorporating or neglecting profiles where a BL is absent makes a strong difference in the resulting BL thickness. Noticeable differences are also seen along the western boundary currents in the northern hemisphere all year long.

To conclude, this new BL thickness climatology (Fig. 5) is probably more realistic than the previous one (de Boyer Montégut et al., 2007), but it should not be considered without the associated porosity ratio (Fig. 4).

\section{Discussion}

As already discussed above, a porosity ratio of $33 \%$ for example means either that only $2 / 3$ of the profiles collected in the area exhibit a BL, or that BLs detected in this area persist over $2 / 3$ of the sampling time, that is one month here. In both cases, however, it means that air-sea interactions are hindered by a BL during $66 \%$ of the sampling period. Our method is however unable to distinguish between time and space variability. A fortiori, it does not allow to quantify the relative importance of spatial or temporal patchiness regarding the climatic impact of BLs. In the classical view, this impact is a one-dimensional process. In this sense, the time patchiness might have more direct implications. But lateral and diffusive effects might also play an important role for the mixed layer heat budget, so that spatial patchiness must also be taken into account.

Concerning time variability, note also that our study does not indicate whether the BL period is continuous over the observed month, and followed by a continuous period where no $\mathrm{BL}$ is present, or whether the BL is present intermittently on a daily time scale for example. These two extreme cases might have themselves different climatic impacts. Porosity as we present it here is an attempt to estimate the life time of monthly BLs and thus their robustness relative to this timescale (one month). It thus depends to some degree on the way in which data are grouped for the statistics. Our study groups them into bins of 12 months.

One way to gain better insight into the problem of quantifying the climatic impact of BLs would be to base the analysis on shorter time intervals, for example weekly bins. Shorter bins however reduce the number of observations in each bin and render the statistics unsafe. The final answer can probably only be obtained through time series with 


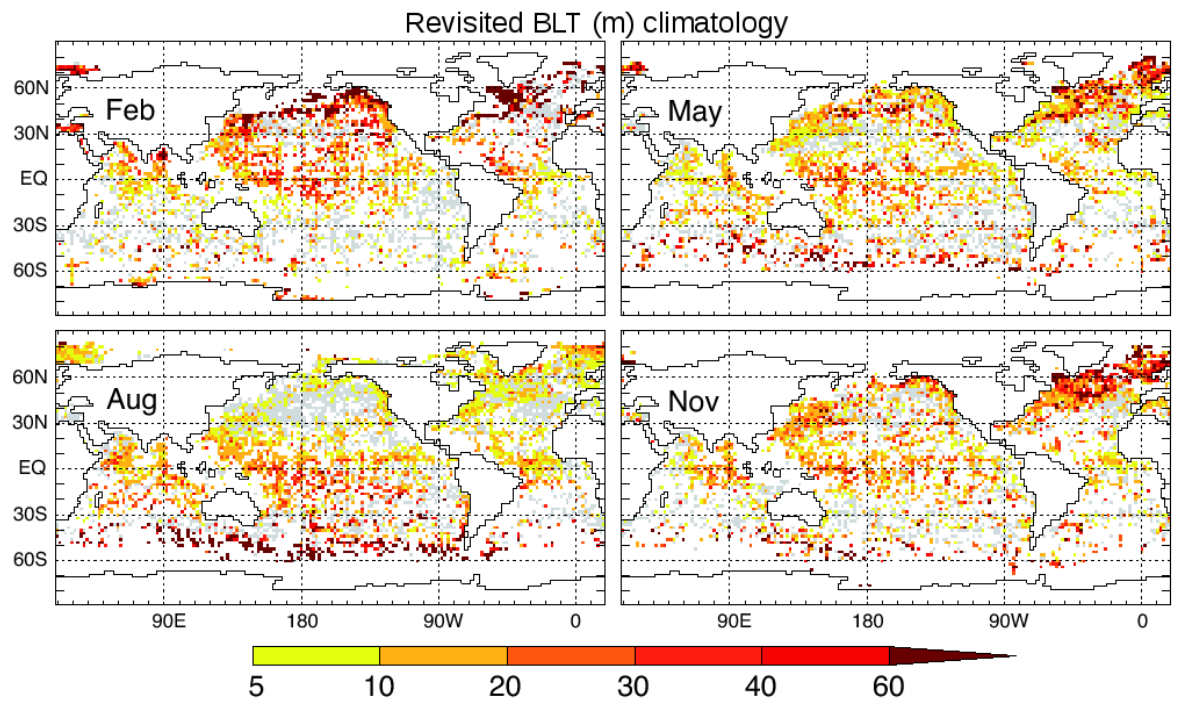

Fig. 5. Selection of 4 monthly maps of the difference $D_{T-02}-D_{\sigma}$ computed as described in Sect. 2.2: for each grid mesh corresponding to a square of $2^{\circ} \times 2^{\circ}$, we plot the median of all differences that are larger than $5 \mathrm{~m}$ and $10 \%$ of $D_{T-02}$. Light grey oceanic areas show grid points where no BL was ever detected. White areas show grid points where less than 5 profiles were available with both $D_{T-02}$ and $D_{\sigma}$ defined. See Fig. S3 for the full 12 monthly maps.

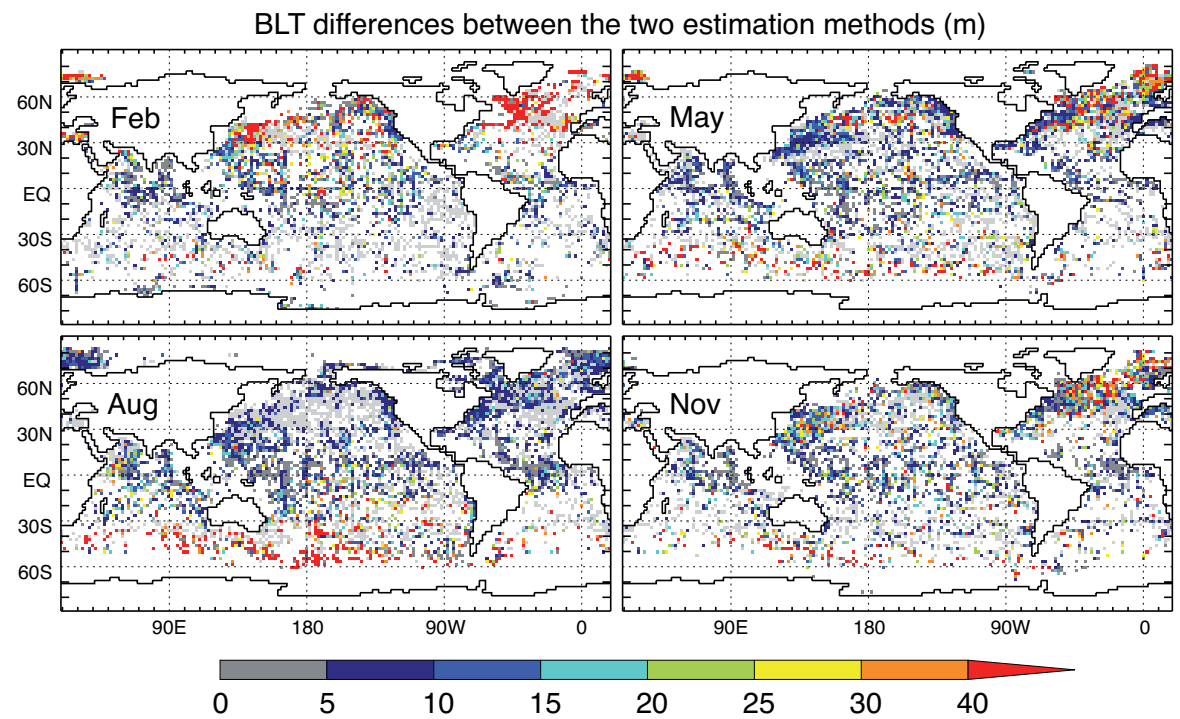

Fig. 6. Selection of 4 monthly maps of the BLT differences between the two computation methods. See Sect. 2.2 for more details. See Fig. S4 for the full 12 monthly maps.

sufficiently high resolution in time. Maybe a detailed assessment of barrier layer porosity requires dedicated field studies in regions of interest that can generate time series capable of resolving processes at time scales of days. With such data in hand, an absolute timescale giving the life expectancy of the BL could be defined. This notion is indeed probably as important as the BL spatial extent in order to evaluate its climatic impact.
Sprintall and McPhaden (1994) carried out such an analysis using mooring data at $0^{\circ}, 165^{\circ} \mathrm{E}$. As indicated earlier, they estimated the dominant timescale of BL thickness in the western equatorial Pacific to be around 12-25 days. It is however difficult to link this result with our study because our definition of porosity is also relative to our space resolution $\left(2^{\circ}\right)$. In the observations obtained in the the central $\mathrm{Pa}$ cific by SSV Robert C. Seamans, a barrier layer was present at 7 stations and absent at 10 stations (Fig. 1), yielding a 
porosity of about 59\%, somewhat larger than but not inconsistent with the value derived from the climatology for March (Fig. 3). With an average station spacing of $40 \mathrm{~nm}(70 \mathrm{~km})$ the resulting porosity could be interpreted as the result of variability in space, perhaps reflecting the localized character of tropical rain storms. However, SSV Robert C. Seamans being a sailing vessel crossing an ocean with moderate to low winds it took the ship more than a week to cover the $1250 \mathrm{~km}$, so some of the observed variability could be the result of changes in time as well. This discussion illustrates the duality between time and space scales regarding the notion of BL porosity.

In our view, another aspect of BLs should be considered to assess their climatic impacts on top of the thickness and porosity: it is the intensity of the salinity stratification. Indeed, we think one should distinguish "strong" BLs, characterized by a robust salinity stratification that would require a relatively intense surface cooling for compensation from "weak" BLs that can potentially be "broken" by a relatively weak surface cooling. This is probably a crucial parameter to estimate the robustness of the BL and its efficiency in limiting the heat exchange between the surface and the cold deeper ocean. Further studies are however needed to define clearly the quantity that should be used to describe this aspect.

As a perspective, we note also that this study does not adress the question of the long term trend in the BL thickness. Obviously, answering this question is limited by the available data. Yet, we propose that attempts could be made to examine this in the more data-rich regions such as the subtropical North Atlantic.

\section{Summary}

This study presents an amended climatology of the global barrier layer thickness of de Boyer Montégut et al. (2007). In addition to using an extended data set, we propose a modified computation method in order to take into account the observed porosity of barrier layers. We name porosity the fact that barrier layers distribution can, at least in some areas, be very uneven in space and in time. This porosity may have important consequences for the climatic impact of BLs.

The new computation method is based on an a priori criterion of BL thickness applied to individual profiles before reducing the data set on a regular grid. It differs from the previous approach where reduction on the grid consisted of taking the median of all individual differences $D_{T-02}-D_{\sigma}$, without considering whether it corresponds to a BL (i.e. $D_{T-02}-D_{\sigma}>0$ ) or not. The new computation goes along with a measure of the ratio $\mathrm{R}$ of the amount of profiles that exhibit a significant BL over the total amount of available profiles, for each grid point. 1-R is a measure of the BL porosity relative to the space and time scales that are considered. The monthly mean differences $D_{T-02}-D_{\sigma}$ computed with the new method and using the extended data set, as well as the monthly porosity ratio, can be downloaded from http:// www.locean-ipsl.upmc.fr $\sim \sim$ cdblod/blt.html. They show that the BL phenomenon potentially occurs nearly everywhere but with different porosity indexes. If the latter is high (over 75 to $90 \%$ ), then the potential impact of the BL for air-sea interactions and climate is likely to be negligible.

One major finding of this analysis is the link between the BL's formation mechanism and the associated porosity index. Note that Tomczak (1995) already mentioned a possible link between BL formation and its persistence in the tropical western Pacific Ocean. Our global product confirms this link for well-known BLs and gives insight into potential formation mechanisms in other areas. In the tropical Indian Ocean (except for the southern Arabian Sea), the western tropical Pacific and Atlantic, BLs are formed by large-scale, mostly advective, processes and they are thus rather impermeable. In these areas, the analysis showed very weak differences (less than $5 \mathrm{~m}$ ) with the previous climatology (de Boyer Montégut et al., 2007). On the other hand, BLs under the ITCZ and in the Arabian Sea in boreal summer develop under the action of mesoscale, turbulent processes that are not resolved by our time and space scales. These BLs were thus logically associated with a larger porosity index. The former computation largely underestimated these BLs and their detection through the new climatology constitutes a major improvement. Concerning the BLs detected equatorward of the subtropical SSS maxima in winter, their intermediate porosity index gives confidence in the fact that some turbulent activity probably plays a role in their formation. A similar distinction could be made at mid to high latitudes: strongly impermeable BLs due to the layering of fresh and cold waters over warmer and saltier waters are found at high latitudes in winter while more permeable BLs are found at mid latitudes in areas of strong turbulent activity (along the Gulf Stream in particular).

Acknowledgements. M. T. thanks the Sea Education Association for the opportunity to participate in voyage S216 of SSV Robert C. Seamans from Hawaii to Tahiti and chief scientist Jan Witting for his support.

Edited by: E. J. M. Delhez

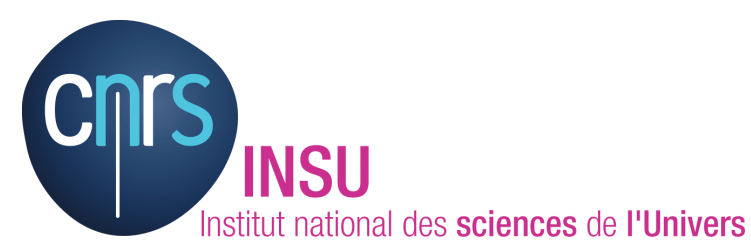

The publication of this article is financed by CNRS-INSU. 


\section{References}

Boyer, T. P., Antonov, J. I., Garcia, H. E., Johnson, D. R., Locarnini, R. A., Mishonov, A. V., Pitcher, M. T., Baranova, O. K., and Smolyar, I. V.: World Ocean Database 2005, NOAA Atlas NESDIS 60, US Government Printing Office, Washington, DC, s. Levitus, edition, 190 pp., 2006.

Cronin, M. F. and McPhaden, M. J.: Barrier layer formation during westerly wind bursts, J. Geophys. Res., 107(C12), 8020, doi:10.1029/2001JC001171, 2002.

de Boyer Montégut, C., Mignot, J., Lazar, A., and Cravatte, S.: Control of salinity on the mixed layer depth in the world ocean. Part I: general description, J. Geophys. Res., 112, C06011, doi:10.1029/2006JC003953, 2007.

de Boyer Montégut, C., Madec, G., Fisher, A. S., Lazar, A., and Iudicone, D.: Mixed layer depth over the global ocean: an examination of profile data and a profile-based climatology, J. Geophys. Res., 109, C12003, doi:10.1029/2004JC002378, 2004.

de Boyer Montégut, C., Durand, F., Bourdallé-Badie, R., and Blanke, B.: Barrier layers in the Arabian Sea during the summer monsoon, in preparation, 2009.

Godfrey, J. S. and Lindstrom, E. J.: The heat budget of the equatorial western Pacific surface mixed layer, J. Geophys. Res., 94, 8007-8017, 1989.
Levitus, S.: Climatological Atlas of the world ocean. Technical report, NOAA Prof. Pap. 13, 163 pp., 1982.

Mignot, J., de Boyer Montégut, C., Lazar, A., and Cravatte, S.: Control of salinity on the mixed layer depth in the world ocean. Part II: tropical and subtropical areas, J. Geophys. Res., 112, C10010, doi:10.1029/2006JC003954, 2007.

Sprintall, J. and Tomczak, M.: Evidence of the barrier layer in the surface layer of the Tropics, J. Geophys. Res., 97, 7305-7316, 1992.

Sprintall, J. and McPhaden, M. J.: Surface layer variations observed in multiyear time series measurements from the western equatorial Pacific, J. Geophys. Res., 99, 973-979, 1994.

Thadathil, P., Muraleedharan, P. M., Somayajulu, Y. K., Gopalakrishna, V. V., and Reddy, G. V.: Seasonal variability of the observed barrier layer in the Arabian Sea, J. Phys. Oceanogr., 38(3), 624-638, 2008.

Tomczak, M.: Salinity variability in the surface layer of the tropical western Pacific Ocean, J. Geophys. Res., 100(C10), 20499 20515, 1995.

WOCE Data Product Committee: WOCE Global Data, version 3.0, Technical Report 180/02, WOCE Int. Project Off., Southampton, UK, 2002

You, Y.: Salinity variability and its role in the barrier-layer formation during TOGA-COARE, J. Phys. Oceanogr., 25(11), 27782807, 1995. 